\title{
ESCOLA, LUGAR E PODER: UMA ANÁLISE GEOGRÁFICA A PARTIR DE SÃO CAETANO DO SUL, SP, BRASIL.
}

\author{
Eduardo Donizeti Girotto*
}

\section{RESUMO}

O presente artigo, resultado de pesquisas desenvolvidas junto ao Programa de Pós-Graduação em Geografia Humana, nível mestrado, da Universidade de São Paulo, tem como objetivo analisar de que forma os interesses políticos locais interferem na organização pedagógica e administrativas das escolas públicas municipais de São Caetano do Sul. Para tanto, a partir de um olhar geográfico, analisamos, com maior detalhe, o caso de uma das principais escolas públicas municipais da cidade, com um olhar investigativo a partir de dentro, que toma a experiência do próprio pesquisador como ponto de partida. A compreensão das práticas sócio-espaciais que ocorrem na cidade, em nossa perspectiva, são fundamentais para o entendimento das relações pedagógicas e políticas que ocorrem na escola, bem como o significado da mesma como espaço social, alvos dos mais diferentes interesses e estratégias de reprodução espacial do poder.

PALAVRAS-CHAVES: Lugar - Poder -Discurso - Ensino - Escola

\section{SCHOOL, PLACE AND POWER: A GEOGRAPHICAL ANALYSIS FROM SAO CAETANO DO SUL, SP, BRAZIL.} ABSTRACT

This paper describes the result of research conducted by the Graduate Program in Human Geography, Master level, University of São Paulo, aims to analyze how the local political interests interfere with the educational and administrative organization of public schools in Sao Caetano do Sul Therefore, from a geographic look, we analyzed in greater detail the case of a major public schools of the city with an investigative look from within, taking the researcher's own experience as starting point. The understanding of socio-spatial practices that occur in the city, in our view, are fundamental to the understanding of pedagogical and political relations that occur at school as well as the meaning of it as social space targets from different interests and strategies of reproduction space power.

KEYWORDS: Place - Power - Speech - Education - School

\section{Introdução}

São Caetano do Sul tem ganhado destaque, nas últimas décadas, por apresentar um dos mais elevados Índices de Desenvolvimento
Humano no Brasil. Em 2000, segundo dados do PNUD $^{1}$, a cidade aparecia na $1^{0}$ colocação nacional, com o IDH de 0,919. A cidade apresenta $100 \%$ de urbanização, contando com acesso à água potável 
e sistema de coleta de esgoto, apesar de ainda não existir tratamento para todo o esgoto coletado. Apresenta também índices elevados de expectativa de vida e de renda per capita. No que concerne a Educação, no ano de 2007, a cidade recebeu o selo do MEC dado a todas as cidades que erradicaram o analfabetismo e, por cinco anos seguidos, alcançou o primeiro lugar em escolaridade no Índice Paulista de Responsabilidade Social publicado pela Fundação
Sistema Estadual de Análise de Dados (SEADE). A cidade apresenta uma rede pública de educação muito bem estruturada, contando com escolas de ensino infantil, fundamental e médio, além de uma universidade subsidiada pela prefeitura. No ano de 2007, foi inaugurada a primeira faculdade pública da cidade, a Fatec ${ }^{2}$ de São Caetano do Sul, que funciona no mesmo prédio da $\mathrm{ETE}^{3}$ Jorge Street.

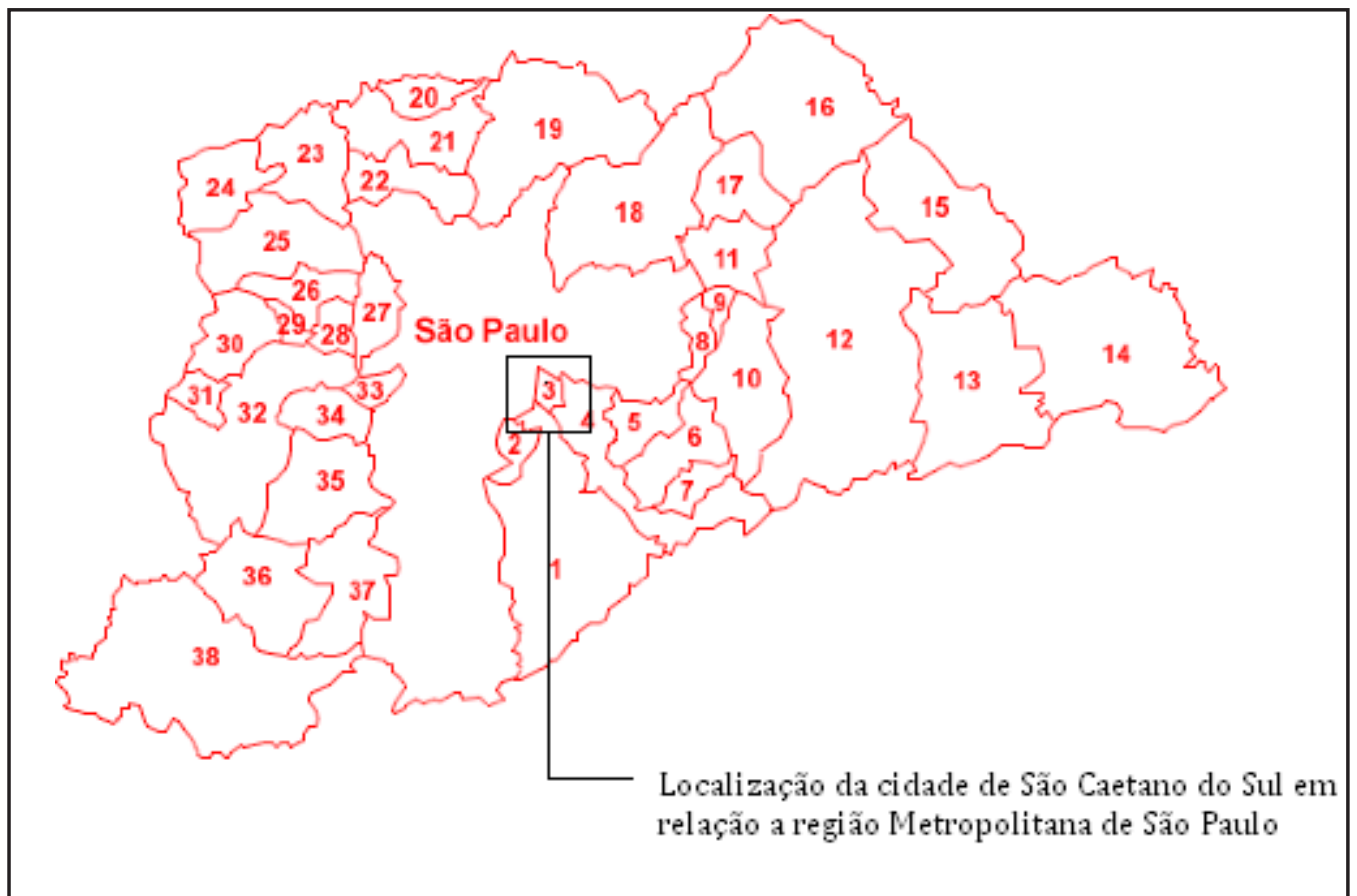

Figura 1: Localização da Cidade de São Caetano do Sul em relação à Região Metropolitana de São Paulo. Fonte: www.saocaetanodosul.sp.gov.br. Mapa sem escala.

Porém, para além do discurso que visa enaltecer uma certa imagem da cidade, faz-se necessário compreender os interesses e estratégias que marcam as práticas sócio-espaciais que ali ocorrem e que tem nas escolas públicas do município um dos seus lócus de realização. Tais práticas, como veremos, estão sustentadas em um discurso histórico-geográfico que busca valorizar determinados grupos políticos da cidade em detrimento de outros. Tal discurso, por sua vez, se realiza também a partir da escola, concebida enquanto espaço de reprodução de determinadas práticas sociais que tem na afirmação de privilégios em detrimento dos direitos um dos seus principais elementos. Ao compreender estas práticas em suas diferentes escalas espaço-temporais, acreditamos poder contribuir na ampliação do entendimento da escola enquanto lugar social, situado e contextualizado, lócus de múltiplos interesses e estratégias que devem ser levados em consideração em qualquer análise geográfica acerca da realidade. 


\section{O desvendamento do lugar}

Um dos elementos que marcam a especificidade das práticas sócio-espaciais encontradas em São Caetano do Sul diz respeito a sua extensão territorial. A cidade possui cerca de $15 \mathrm{~km}^{2}$, o que possibilita aos seus moradores relações sócio-espaciais que nas cidades de maior porte são pouco presentes. Aquela sensação de não-reconhecimento, de um entre tantos que marca a realidade dos grandes centros urbanos do mundo e que tem como elemento central o fenômeno da massa, descrito e analisado por Elias Canetti (2005), é dificilmente encontrado nas falas dos moradores de São Caetano do Sul e dos alunos que frequentam a escola estudada. Para muitos, a cidade ainda se organiza como uma antiga comunidade de imigrantes que tem como elemento central certo senso de solidariedade que pressupõe o reconhecimento do outro e de suas condições. No imaginário da população, como pudemos perceber em entrevistas e conversas informais realizadas com moradores e alunos, a idéia de "aldeia", de pertencimento surge como um dos elementos definidores do que vem a ser as características das relações sócio-espaciais em São Caetano do Sul.

Esta sensação de pertencimento resulta também na construção de uma em uma extensa história local que pode ser facilmente consultada nas publicações realizadas pela fundação Pró-memória. Tal fundação, junto com o Museu Municipal, foram criações da municipalidade com o objetivo de reconstruir a história local de São Caetano do Sul, buscando inseri-la na história de São Paulo e do Brasil. Tal história local é difundida por meio das escolas e se reproduz, muitas vezes, sem o questionamento e a crítica necessária para sua compreensão.

Em seu livro Subúrbio, Martins (1992) analisa a formação do núcleo colonial de São Caetano do Sul. Segundo o autor, o subúrbio se define enquanto o componente rural do urbano. No subúrbio, as relações que os moradores estabelecem entre si e com o lugar dizem respeito ainda aos resquícios da lógica do rural. O que define, muitas vezes, a posição social no interior desta sociabilidade de São Caetano do Sul são as relações de parentesco que um determinado sobrenome revela. É possível perceber isso no contato diário com os alunos. Os mesmos se reconhecem e são reconhecidos muitas vezes mais pelo nome que carregam do que pela condição financeira que possuem. Tal nome, por sua vez, revela uma posição também na tão difundida história local. Participar de uma família, portanto, significar estar mais próximo ou distante desta história oficial da cidade. Aqueles, porém, que não carregam tais sobrenomes sofrem com o peso do desconhecimento e com as consequências políticas daí advindas.

Desde o início do processo de ocupação territorial de São Caetano do Sul, os vínculos estabelecidos pelas primeiras famílias foram fortalecidos, em certa medida, em decorrência da difícil situação econômica e de reprodução da vida em que a maioria dos moradores se encontravam naquele momento. Estas dificuldades resultavam também da distância existente entre a cidade neste caso, São Paulo - e o subúrbio, como se, pelo menos em aparência, o subúrbio fosse a negação da cidade. A ajuda mútua, o estreitamento dos laços sociais foram as alternativas encontradas para que se pudesse suprir a ausência da cidade, representação do poder político. No vazio deixado pela ausência da cidade, os moradores recriaram suas identidades enquanto identidades, também, coletivas. Criou-se, neste sentido, a idéia de aldeia, de sociedade fechada, identificada pelo sobrenome, característica marcante da sociedade atual de São Caetano do Sul.

\section{A história local e a criação da "comunidade".}

Segundo MARTINS (1992:13), "na história local e cotidiana estão as circunstâncias da História". No caso de São Caetano, seu desenvolvimento se deu, como vimos, a margem do desenvolvimento da cidade de São Paulo. É na cidade que se passa a história oficial, a história relatada, escrita e difundida por todo o país. No subúrbio, a História oficial chega como fragmento, como pedaço irreconhecível do que acontece na cidade. Neste sentido, é negado ao subúrbio participar da história oficial, no sentido em que não 
Ihe é permitido nela aparecer. Na história oficial, o subúrbio aparece em poucas páginas, dedicadas talvez a algum acontecimento de relevância secundária. Esta negação da história a qual o subúrbio está submetido resulta num processo de resistência dos suburbanos, a criação de outra história, que seja, a história vista a partir do subúrbio, a partir do fragmento. Segundo Martins, A população local se defende contra esse vazio de sentido, essa marginalidade histórica. Os esforços de seus moradores e cronistas são no sentido de dar aos pequenos atos de todos os dias e as biografias esvaídas (e construídas) no trabalho duro de muitas décadas o sentido do épico, do ato monumental dos heróis civilizadores, dos grandes acontecimentos que selam o destino das sociedades. (MARTINS, 1992:14)

A história como resistência é também resistência do fragmento, resistência daqueles que buscam na história a afirmação de privilégios em detrimento dos direitos de todos. A história local é a identidade que busca garantir a existência da comunidade, ou melhor, de uma parte dela. Busca, em um determinado passado comum, em um mito fundador, em uma certa narrativa, os elementos, ao mesmo tempo, de identidade e alteridade, que permitam reconhecer os iguais e os diferentes da cidade. Como toda a história, a história local de São Caetano é contada a partir de um ponto de vista, o ponto de vista daqueles que possuem, ou que afirmam possuir, a autoridade para contá-la. Esta autoridade se baseia em outro importante elemento que se quer reproduzir, que seja, a tradição da comunidade.

Zygmunt Bauman, em livro sobre o assunto, apresenta as implicações desta idéia na atualidade. Para o autor, a idéia de comunidade sempre esteve associada a uma certa positividade, marcada pelo fato de que viver em comunidade é melhor do que suportar a solidão da vida. Para o autor, porém, é preciso superar esta visão unilateral para que se possa compreender a relação entre o ressurgimento das comunidades e o momento atual do mundo. Para Bauman, existe uma clara diferença entre a comunidade ideal, sempre positiva, e a comunidade realmente existente. Para o autor, a comunidade realmente existente, exigiria rigorosa obediência em troca dos serviços que presta ou promete prestar. Você quer segurança? Abra mão de sua liberdade, ou pelo menos boa parte dela. Você quer poder confiar? Não confie em ninguém de fora da comunidade. Você quer entendimento mútuo? Não fale com estranhos nem fale línguas estrangeiras. Você quer essa sensação aconchegante de lar? Ponha alarmes em sua porta e câmeras de TV no acesso. Você quer proteção? Não acolha estranhos e abstenha-se de agir de modo esquisito ou de ter pensamentos bizarros. (BAUMAN, 2003: 10)

Participar da comunidade, como vimos, requer aceitar as regras que nela estão postas. Qualquer ação que descontente os participantes de uma determinada comunidade, resulta na perda da proteção que esta lhe garante. Dessa maneira, a comunidade funciona numa relação tênue que tem como principal elemento a definição do "nós" e do "eles". A construção de uma identidade comunitária se faz na definição clara de sua alteridade sendo que nesta relação os dois lados se tornam estigmas, imagens estanques (ELIAS, 2000).

No caso de São Caetano do Sul, esta construção da história local como fragmento da história se pautará no desenvolvimento de uma auto-imagem da comunidade imaginária, alicerçada principalmente no ideal de italianidade. Segundo Martins,

Se a religião foi o primeiro elemento de aglutinação, ganhou força muito rapidamente a italianidade. A qual, aliás, não fora real para a maioria dos colonos chegados a São Caetano. A maioria deles nascera antes que se consumasse a unidade nacional italiana, antes que a Itália existisse como tal. A Italianidade foi, portanto, 
construída na adversidade das condições de vida que o imigrante encontrou no Brasil (MARTINS,1992: 189).

O ideal de italianidade permitiu aos migrantes fundadores do núcleo criarem uma identidade coletiva capaz de fomentar a solidariedade entre o grupo e para que assim o mesmo pudesse enfrentar as dificuldades relacionadas às primeiras décadas da colonização. Passadas as primeiras dificuldades, o ideal de italianidade passa a ser retomado no sentido de fomentar a auto-imagem dos grupos tradicionais de São Caetano do Sul com o intuito de marcar a diferença deste grupo em relação aos outros que passavam a compor a estrutura demográfica da região do $A B C$, principalmente os migrantes nordestinos.

Baseada no ideal das famílias fundadoras, a história-mito de São Caetano do Sul oculta mais do que revela. Pouco deixa vir a tona a história das outras famílias, das que vieram e foram embora, no início do núcleo, das que chegaram com a expansão industrial e passaram a ocupar as periferias da cidade e que tiveram negados a própria identidade de pertencentes a cidade. A história de São Caetano do Sul, organizada, escrita e compilada pela e para a reprodução do poder, é a história contada pelos vencedores, por aqueles que vêm na pseudo-idéia de fundação constructo estratégico de poder, elemento legitimador de diferenciação.

\section{O discurso histórico-geográfico, valorização urbana e a reprodução do poder local}

Construído com base no Ideal da comunidade de tradição, pautada na italianidade, o discurso histórico-geográfico oficial de São Caetano do Sul é hoje incorporado pelos novos detentores do poder local, com o intuito de enfrentar a crise financeira da cidade decorrente do fechamento de muitas indústrias fundamentais ao crescimento econômico da mesma. À este discurso, associase outro, mais dinâmico e moderno, que busca colocar a cidade no hall das cidades mundiais, transformando-a em uma mercadoria como outra qualquer. Com ele, busca-se construir um processo de valorização dos terrenos urbanos, associando a imagem da cidade a um certo ideal de qualidade de vida, também associado ao conceito de comunidade. Neste discurso, vende-se a cidade ideal, sem problemas urbanos, marcada pela qualidade de vida sócio-ambiental, pelos elevados índices de IDH. Vende-se a cidade sem favelas, sem periferia, no qual o direito à cidade, pelo menos em discurso, está a todos garantido. Vende-se a imagem de alguns bairros, de algumas famílias; ocultam-se, porém, tantas outras que, por vários motivos, não devem fazer parte deste marketing urbano que se quer construir.

1. $\quad$ Este marketing urbano, para o qual VAINER (ANO) chama a atenção aparece no discurso oficial dos representantes do planejamento urbano da cidade de São Caetano do Sul. Em sua dissertação de Mestrado, Enio Moro Junior, arquiteto da Prefeitura Municipal de São Caetano do Sul, apresenta o que considera algumas estratégias fundamentais para que a cidade possa enfrentar as novas dinâmicas relacionadas a urbanização, principalmente no que diz respeito a transição de cidade industrial para a cidade de serviços especializados. Entre as iniciativas defendidas pelo autor, gostaríamos aqui de destacar duas:

2. - Renovação urbana: possibilidade de reciclagem de instalações ou áreas tornadas disponíveis pela evasão industrial para a renovação urbana e a implantação/instalação de atividades de alcance sub-regional e metropolitano.

3. - Imagem da Cidade: identificação de elementos urbanos característicos que garantam uma identidade visual auxiliando a percepção das singularidades de desenho e imagem da cidade (MORO JR., 1998:134)

4. Nestes dois trechos descritos acima, fica explícito a estratégia de intervenção urbana em São Caetano do Sul que, em certa medida, e pela própria influência do autor, tem sido posto em prática. De um lado, a abertura de novas frentes de especulação imobiliária aproveitando-se de áreas deixadas pelas indústrias no processo que o autor denomina de evasão industrial. São essas áreas que tem sido utilizada na construção de novos empreendimentos imobiliários de alto padrão, bem como na atração de atividades do setor terciário. Do outro lado, a construção de uma imagem da 
cidade, que busca ressaltar a singularidade do desenho. $O$ realce da singularidade significa, por sua vez, ocultar as disparidades, as desigualdades sócio-espaciais que marcam a urbanização de São Caetano do Sul e todo o processo de urbanização sob a lógica do capital.

5 .

Ao mesmo tempo, a imagem da cidade é um dos elementos fundamentais para se compreender a difusão do discurso históricogeográfico presente em São Caetano do Sul. Como representantes dos interesses ligados ao processo de revalorização urbana de São Caetano do Sul, muitos dos grupos tradicionais da cidade incorporam tal discurso a imagem nova da cidade que se quer produzir. O passado torna-se, portanto, justificativa e legitimação do presente, bem como garantia de futuro para os que ali escolherão morar. Nesse caso, como nos aponta Bauman, na invenção de uma tradição

6. O que importa são o presente e o futuro comuns; a única importância de um passado comum é modelar o presente e o futuro e manter o curso com um pouco mais de facilidade. (BAUMAN, 2000:137)

$7 . \quad$ Dessa maneira, construir uma imagem da cidade significa, ao mesmo tempo, ressaltar traços a serem lembrados, ocultar o que precisa ser esquecido. A imagem da cidade, a ser vendida, local, regional, nacional e globalmente, é uma marca do planejamento urbano na atualidade e pode ser verificada nas estratégias espaciais que têm sido colocadas em práticas na cidade de São Caetano do Sul. Vale, portanto, retomar a questão feita por VAINER em seu texto: "o que é que, afinal de contas, se vende quando se põe a venda uma cidade?" (VAINER, 2002: 78)

Para que, porém, este processo se realize faz necessário criar as condições estruturais para que o discurso se realize enquanto prática sócioespacial. E nesta tarefa as escolas municipais de São Caetano do Sul tem desempenhado um papel essencial. Partamos então, agora, à análise da escola estudada.

\section{Da cidade à escola}

Criada na década de 1960 da necessidade de formação de mão de obra técnica para as diferentes empresas da cidade, a escola estudada é uma das escolas mais antigas e tradicionais de São Caetano do Sul Apesar de seu gigantismo, a escola possui um nível de organização que se pauta por uma idéia de qualidade de ensino alicerçada nos resultados obtidos em avaliações nacionais, como o ENEM. A seriação e a reprovação são práticas existentes e segundo alguns pais e professores, em conversas informais, o que garante "a qualidade" de ensino em toda a rede municipal é a não adoção do sistema de progressão continuada e a continuidade da reprovação, somado a um intenso investimento no sentido de possibilitar aos alunos reforço escolar. O número de alunos por sala é limitado a 35 , sendo que, em algumas não ultrapassa 25. A escola é equipada com laboratório de ciências, escritório modelo, laboratório de publicidade, laboratórios de informática, anfiteatro, ginásio poliesportivo, laboratório de fotografia, biblioteca.

8. $\quad O$ ingresso no Ensino Médio é feito por meio de vestibulinho apesar de alguns alunos afirmarem que o mesmo ocorra, muitas vezes, por intermediação do padrinho político. As questões relacionadas ao vestibulinho (forma de aplicação e de correção, elaboração da prova, entre outras) são reveladoras de conflitos existentes entre os diferentes grupos políticos da cidade. Em um destes conflitos, houve intervenção direta da diretoria de educação de São Caetano do Sul na aplicação e correção do vestibulinho de 2008. Como representam grupos políticos de visões opostos, a diretora de educação e a diretora da escola, no ano de 2008, fizeram daquele momento, comum na rotina da escola, lócus de disputa de poder que marcam algumas das relações sócio-espaciais que ocorrem em São Caetano do Sul.

9.

Por se tratar da escola mais tradicional de São Caetano do Sul, os alunos que nela ingressam possuem um nível de renda elevado (classes B e $C$, em sua grande maioria), além de muitos deles serem filhos de famílias importantes no quadro político da cidade, sendo muito comum a presença de filhos e parentes de vereadores.

10. Com o desenvolvimento de minha prática pedagógica no interior da escola estudada entre os anos de 2007 e 2010 pude constatar que muito do que ocorre no interior desta unidade 
escolar, diz respeito às dinâmicas sócio-espaciais relacionadas a especificidades políticas e sociais existentes na cidade. Ao assumir as aulas no Alcina, lembro-me bem da sensação de estranhamento que tive a primeira vez que entrei na sala dos professores. No período da manhã, são cerca de trinta professores que se reúnem na hora da entrada, do intervalo e, rapidamente, na saída. Observando as conversas e as relações que ali se estabeleciam, percebi que poucas delas versavam sobre reclamações referentes a problemas enfrentados na educação em diferentes lugares: salários, infra-estrutura, relação professoresdireção. Senti-me feliz porque a primeira impressão era a de que se ali tais assuntos não se discutiam é porque tais problemas não existiam naquele lugar. Infelizmente, pouco tempo depois descobri que aquela primeira impressão era apenas a projeção de um professor que espera que sua profissão seja definitivamente reconhecida e respeitada.

Por que, então, tais assuntos não se discutiam abertamente naquela sala? Foi a partir desta pergunta que comecei a compreender as relações que existiam entre a escola, lugar e poder, tendo como pano de fundo minhas práticas profissionais como professor.

Diferente de algumas outras redes de ensino, não existem concursos públicos para os cargos de diretor, assistente de direção e coordenador pedagógico na rede municipal de ensino de São Caetano do Sul. Tais cargos são considerados de confiança e de indicação direta do próprio prefeito, com interferência de vereadores e de figuras importantes nos quadros políticos da cidade. A cada mudança de mandato, muda-se o diretor e sua equipe de trabalho, ficando assim os professores e os alunos a mercê da direção que seguem os ventos políticos na cidade. A escola estudada, por se tratar de uma das mais importantes na cidade, possui os cargos, na área de educação, mais cobiçados pelos aliados políticos de todo prefeito eleito. Nela, portanto, se revelam também às relações de poder que perpassam a política em São Caetano do Sul. O sobrenome e o apadrinhamento político são os elementos fundamentais que definem quem será designado para ocupar um determinado cargo. Para o prefeito, é fundamental ter tais famílias como aliados políticos, principalmente pelo fato de poder usar a tradição das mesmas, ratificada muitas vezes no discurso histórico-geográfico dominante na cidade, como uma das estratégias políticas pré-eleição.

Para quem está acostumado com o horário político na televisão e no rádio, com os outdoors e todas as caríssimas campanhas de marketing que marcam os períodos eleitorais nas grandes metrópoles, soa estranho que a campanha política, em uma cidade há menos de 20 quilômetros do centro da maior cidade do país, aconteça, principalmente, a partir do tradicional boca-a-boca. Porém, o contexto urbano de São Caetano do Sul propicia que tal fenômeno ocorra. E é exatamente esta particularidade encontrada na cidade que ajuda a explicar a relação existente entre os políticos locais e as famílias tradicionais da cidade. Em uma articulação política e estratégica, os candidatos se apóiam na autoridade que os moradores de São Caetano do Sul reconhecem nestas famílias, principalmente pelo discurso que os remete a idéia de fundação e de progresso da cidade, para legitimarem seus discursos e práticas que, muitas vezes, ocultam os interesses particulares que ali existem. Em certa medida, a construção de uma história local pautada nas histórias das famílias fundadoras foi apropriado e articulado em uma estratégia de reprodução dos poderes políticos na cidade.

Durante os primeiros anos em que lecionei no Alcina, como disse anteriormente, foi freqüente presenciar a ida de políticos locais na escola e nos eventos por ela organizada. Durante o ano eleitoral de 2008 , o prefeito esteve três vezes na escola para anunciar propostas e inaugurar obras. O presidente da Câmara compareceu mais vezes: foram seis ao total, contabilizando almoços e confraternizações. Todos estes elementos iam, aos poucos, revelando-me o significado político e social da escola em sua relação com o lugar.

Porém, o que mais me intrigava era saber como deveria ser minha atuação como professor de geografia naquele determinado contexto? Havia tanto a se explorar e tantos riscos a correr. Sabia que uma interpretação crítica das relações de poder e das estratégias políticas que tinham na escola um dos seus lócus de realização poderia me custar o cargo. Comentava com os 
outros professores sobre este meu incomodo e era, na maioria das vezes, aconselhado a esquecer isto e seguir o programa.

O que significa, porém, seguir o programa? Em nossa perspectiva, tal prática é reveladora de uma certa negação do lugar, visto que o mesmo não surge como objeto de pesquisa, como elemento a ser desvendado, repleto de conflitos, interesses e estratégias que permeiam seus diferentes sujeitos. As contradições espaço-temporais presentes no lugar são relegadas para segundo plano ou até mesmo negadas em detrimento de um programa descontextualizado. Em alguns casos, o lugar surge como homogêneo, como portador da marca da cidade que perpassa a tudo e a todos. Negar o lugar em suas particularidades e contradições pode ser entendido também como estratégia política de reprodução do status quo. A adoção de um modelo educacional que privilegia conteúdos gerais que de forma alguma são contextualizados e, por isso, apresentam-se como realidades em si mesmas, são algumas das práticas pedagógicas adotadas na escola estudada e que revelam uma das formas pelas quais o discurso histórico-geográfico da cidade de São Caetano do Sul é reproduzido. A cidade não surge como elemento de análise, não é posta em movimento, discussão, análise. Ao contrário, na fala das diferentes autoridades escolares o que aparece é a reprodução da do discurso oficial, da comunidade imaginária, da imagem da cidade que visa ocultar as contradições que marcam a cidade real.

De forma geral, esta concepção pedagógica que pressupõem a aplicação do programa como único objetivo resultou, por parte dos docentes da unidade escolar, em um certo descrédito em relação a importância que possuem no interior do processo de ensino aprendizagem. Isso se revela, por exemplo, no momento de planejamento do ano letivo. Como pude perceber, para além do diálogo e da construção de um projeto de educação a ser desenvolvido, domina certo conformismo em copiar, ano após ano, os programas anteriores, como se cumprir os conteúdos que ali estão postos fossem os únicos objetivos a serem alcançados no decorrer de um ano letivo. A ação crítica e criativa que pressupõe todo trabalho de planejamento e que é uma das bases e fundamentos para a construção do projeto político pedagógico é relegada à segundo plano, muitas vezes chegando a inexistir. Porém, como veremos mais adiante, este conformismo dos professores é também uma estratégia política frente às condições de trabalho existentes na rede municipal de educação de São Caetano do Sul.

Da mesma forma, para muitos alunos, a repetição de métodos e de conteúdos, em um trabalho que lembra muitas vezes uma linha de produção em série, transforma a escola em um fardo a ser carregado. Muitos deles vêem pouco significado para além das questões burocráticas que permeiam a escola. Lembro-me de uma conversa que tive com uma das professoras de Sociologia da escola. No final do ano letivo de 2008, a professora me procurou para conversarmos sobre o rendimento de algumas salas de $3^{\circ}$ ano do Ensino Médio. Para a professora, era difícil compreender a tamanha apatia que acometia aqueles alunos a poucos meses de se formarem, de avançarem em seus estudos e em suas vidas profissionais. Propus-se, então, para a professora "bater um papo" com os alunos, tentar entender o que estava acontecendo e assim o fiz. Foi uma conversa extremamente reveladora. Nela pude perceber os significados de algumas práticas adotadas na escola e que refletiam claramente no imaginário e na forma como os alunos a concebiam. Segundo os alunos, por ser uma escola, como vimos, bastante tradicional e na qual a cobrança sobre os mesmos é muito elevada, eles tiveram que "aprender a jogar o jogo". Como toda a ênfase do processo de avaliação está posta nas semanas de provas, as energias dos alunos ficam nelas concentradas. É neste momento que criam estratégias tanto de estudo como de cola. Passada a semana de prova, tendo alcançado ou não o resultado necessário, é chegado o momento de repor as forças, momento da apatia em sala de aula, afinal de contas, ciclicamente, uma semana de provas os espera logo mais.

Neste sentido, a escola se torna uma mera repetição de avaliações sobre conteúdos gerais que pouco ou nada dizem respeito a experiência dos alunos acerca da cidade em que vivem. O discurso da qualidade que ressalta o 
quantitativo, a nota, busca ocultar o fato de que a cidadania, como exercício pleno do direito à cidade (LEFEBVRE, 2004), de pensá-la e vivê-la em suas múltiplas dimensões não faz parte dos objetivos a serem alcançados pelo "programa escolar".

Durante os encontros pedagógicos, pude compreender o que mais incomodava os professores em suas praticas cotidianas. Entre as principais questões, falavam com tristeza das muitas mudanças ocorridas e da pouca participação que tinham nelas. Nesta tristeza, revelavam um pouco da impotência que sentiam frente aquela realidade. O poder centralizado e centralizador concebia o professor como mero cumpridor de ordens e de programas, decididos em reuniões fechadas, definidos pelos conteúdos pré-determinados e que faziam parte de estratégias políticas que ultrapassavam os muros da escola. Pouco ou nada restava de poder e autonomia aos professores que acabavam, assim, apenas executando as ordens que vinham da Secretaria Municipal de Educação. Esta sensação de impotência, por sua vez, resultava em um afastamento cada vez maior dos professores da escola como lugar de formação e produção de conhecimento, bem como de uma leitura mais crítica e criativa das problemáticas locais que interferiam diretamente em seu trabalho. O cansaço decorrente das tantas mudanças de administração que resultavam, por sua vez, em mudanças no projeto da escola, trazia aos professores a sensação de que, naquele contexto, o mais correto a fazer era se adaptar a tudo o que ocorria ao bel prazer dos ventos políticos da cidade. Para muitos, a escola, naquele modelo de gestão, significava mais lugar de repressão, de ordenação, do que possibilidade de partilha e de formação profissional.

Em outro encontro pedagógico, esta sensação de impotência da maioria dos professores ficou mais clara. Indagado sobre o que estava achando sobre a escola, disse-Ihes que me sentia um pouco confuso e que tal confusão decorria da seguinte situação: ao mesmo tempo em que estava em uma escola dotada de uma excelente infraestrutura, com professores altamente qualificados, alunos interessados, sentia-me aprisionado a um modelo educacional pouco significativo para a aprendizagem do aluno e para as minhas práticas profissionais e repleto de interesses e estratégias políticas. Disse-lhes, também, que não sabia se iria continuar no outro ano e que tal decisão dependia da resposta a pergunta que a seguir faria: qual a força política que tínhamos, como grupo de profissionais, para mudar aquela realidade? À pergunta seguiu um demorado silêncio. Depois de alguns minutos, alguns professores sorriram, outros desviaram o olhar. Foi então que obtive a resposta pela voz de um colega: "o problema é esse, nenhuma". Ali pude compreender o dilema na qual estavam inseridos tais professores e no qual, naquele momento, acabava de me inserir. Tratava-se, portanto, de um embate político que perpassava as relações entre os diferentes sujeitos da educação e o lugar no qual estão inseridos e que com suas práticas sócio-espaciais ajudam a configurar. Por mais que a escola se negasse em discutir as questões relacionadas ao lugar, eram elas, em grande medidas, que interferiam diretamente naquilo que ocorria no interior da escola. Era preciso, portanto, repensar a relação entre escola e lugar no interior do Alcina.

A experiência advinda das discussões ocorridas durantes os encontros pedagógicos me permitiu compreender uma outra perspectiva da escola a qual, até aquele momento, ainda não tinha tido acesso. Tratava-se daquilo que não é dito, do que está oculto nas entrelinhas da cultura escola, mas que também determina, de certa maneira, as relações sócio-espaciais que ali ocorrem. De certa maneira, o não dito revela as estruturas que permeiam as relações de poder na escola, permitindo ao pesquisador compreender determinadas funções e lugares sociais que cada um dos sujeitos que fazem parte destas relações ocupam nesta determinada estrutura. Não se trata, porém, de uma estrutura pré-determinada. Ao contrário, são as relações em sua dinâmica que configuram e reconfiguram as estruturas de poder. Os lugares e as funções sociais não são fixos. Um mesmo sujeito pode ocupar diferentes lugares e funções sociais numa mesma estrutura dependendo da inter-relação que desenvolve com outros sujeitos, em suas funções e lugares sociais.

Como vimos, inseridos naquele contexto, os professores deparavam-se com uma série de dilemas éticos e morais que perpassavam 
sua prática docente. Com o tempo, pude perceber que aquele silêncio inicial, que havia presenciado na sala dos professores e que tinha tomado minha atenção, não significava passividade ou sinal de submissão; era antes questão de sobrevivência profissional, estratégia política fundamental para que os professores, imersos naquela determinada estrutura de poder, pudessem se reproduzir. Tudo na escola girava em torno da aceitação maior ou menor que os professores tinham daquele modelo de educação ali implantado e que, no fundo, reproduziu um modelo de cidade como mercadoria.

Um dos exemplos que pude presenciar e que revela as estratégias de controle e de submissão na qual estavam inseridos os professores diz respeito ao processo de atribuição de aulas. A atribuição é feita a critério da diretora da unidade escolar. Em certa medida, pautam-se em atributos subjetivos. Dependem da relação que o professor possui com aquele modelo educacional ali implantado e com a figura que o representa, ou seja, a diretora da escola. O bom professor é, portanto, o que se submete totalmente aquele modelo, mesmo que para isso tenha que abrir mão do próprio significado da educação. Para este professor submisso, considerado eficiente, o maior número de aulas é oferecido. Para os outros que não se encaixam neste perfil, restam às últimas opções. Há, portanto, um critério personalista no processo de atribuição de aulas que acentua o caráter autoritário do modelo de gestão educacional implementado na escola estudada.

E com isso, surge uma clara diferenciação entre os professores no que diz respeito à aceitação ou não das regras impostas pela direção da escola. Há os professores que, assim como os alunos, aprenderam a "jogar o jogo". Fazem de tudo para não serem notados. Nunca expressam suas opiniões e pensamentos sobre as questões pedagógicas e políticas que ali se configuram. Suas críticas, feitas em voz baixa e com o menor número possível de pessoas, são mais direcionadas a determinados personagens do que ao modelo de gestão ali implementado. Na visão da direção da unidade escolar, são considerados professores bons porque, simplesmente "não dão trabalho", ou seja, não criam questionamentos para aquilo que, na visão da direção, deveria ser cumprido sem que maiores entraves fossem levantados.

Por outro lado, existem os professores que não se furtam de emitir opiniões e de deixar bem claro suas posições políticas e pedagógicas. Correm o risco de, em um modelo de gestão autoritário, propor o diálogo e a democracia nas tomadas de decisões acerca da organização e dos projetos que envolvem a escola. Lembrome de um professora de história, há mais de 23 anos lecionando na escola, que em nenhum momento deixava de se posicionar. Era odiada pela diretora que entendia que as opiniões emitidas pela professora eram ataques pessoais e não direcionados ao modelo de educação ali implementado. Muitas vezes, tal professora era voz única em defesa dos direitos dos alunos e dos professores. Apesar das represálias, não abria mão dos seus ideais. No final de 2008 , em decorrência também da falta de sentido do fazer pedagógico no interior de uma gestão escolar autoritária, tal professora inscreveu-se no programa de demissão voluntária da Prefeitura de São Caetano do Sul.

Neste sentido, o cotidiano escolar se torna momento de cumprimento burocrático de um processo relacionado à estrutura de poder da escola. Nele, suas regras e procedimentos estão claros. Quanto mais tempo um professor permanecer em silêncio, maiores serão as suas oportunidades de se manter no mesmo lugar e na mesma função dentro da estrutura de poder da escola. Em certo sentido, é um estímulo para que o professor não se manifeste, para que não emita sua opinião e que, portanto, continue a não participar das decisões e dos rumos da escola. Porém, tal estrutura não se configura ao acaso. Só pode ser entendida a partir da compreensão dos interesses e estratégias que marcam as relações de poder na cidade de São Caetano do Sul. Nestas relações, a escola pública tem sua função prédefinida. Cabe-Ihe, segundo os poderes locais, criar as condições para que o discurso da cidade se reproduza como realidade. Como pré-requisito para esta reprodução, está a necessidade do silêncio de alunos e professores que já não conseguem ver sentido naquilo que realizam diariamente. 


\section{Considerações finais}

Como, então, pensar a educação a partir deste modelo de gestão pautado no silencio e na aceitação de normas, regras e opiniões que muitas vezes ferem a própria ética docente? Pode um professor burocratizado pela ordem do poder tornar-se sujeito de suas próprias práticas? Qual o preço, profissional inclusive, que deve se pagar ao trazer o lugar, em todas as suas contradições para o interior da escola, inserindo-o como elemento a ser analisado, compreendido e criticado?

A escola, pensada como espaço social, público e coletivo ao mesmo tempo, na qual sujeitos se relacionam baseados em suas intencionalidades e não-intencionalidades, fica em segundo plano nas preocupações dos diferentes sujeitos da educação, que nesta lógica cotidiana, estão, em certa medida, isolados. Enquanto isso, múltiplos interesses invadem a esfera escolar e sem encontrar grande resistência, já que a lógica do isolamento dos sujeitos é reinante, altera-a em prol de benefícios próprios.

É isso o que constatamos na escola estudada. Há pouca ou nenhuma resistência as mudanças resultantes de intervenções políticas que ocorrem na escola. E não há, porque em certa medida, os professores não se sentem parte de um grupo. Não se sentem também responsáveis pelo projeto político-pedagógico daquela instituição que cada vez mais fica refém das mudanças políticas que ocorrem na cidade. Levados que são a se preocuparem mais com questões relacionadas a sua evolução funcional, negando-Ihes o tempo de reflexão e construção de práticas coletivas, os professores sentem-se claramente isolados e com pouco ou nenhum poder político para resistir as transformações que a cada instante ocorre e que se pautam mais em interesses políticos do que pedagógicos.

O silêncio que havia encontrado na sala dos professores no primeiro dia em que cheguei a escola já não possuía mais o mesmo significado. Aos poucos fui percebendo que o silêncio era sinal da presença do poder que vigia, seja pela figura sempre presente do prefeito (pela foto na sala dos professores ou por sua presença física), seja pela entrada, sem prévio aviso, de membros da direção da escola, do poder que está escola, no lugar, na cidade e que redefine e determina certas relações sócio-espaciais. Para além de uma leitura simplista da atuação dos professores e de suas práticas, a compreensão do significado daquele silêncio me permitiu compreender como as relações de poder estruturam as relações sociais na escola, interferindo nas práticas de alunos e professores e, contribuindo, em certa medida, para reprodução da estrutura de poder que encontramos na cidade.

Para muitos professores, principalmente aos mais antigos na profissão, resta voltar-se para dentro da sala de aula e ali cumprir a função para a qual foram designados, sem questionar, sem se perguntar a quem interessa que tais elementos sejam dessa maneira e não de outra. Isolados na sala de aula, pouco importa aos professores compreenderem as dinâmicas sóciopolíticas que dizem respeito ao lugar no qual a escola, como espaço-social, está inserida. O lugar surge apenas como sustentáculo de determinadas relações que com o decorrer do tempo passam a ser encaradas como naturais, como próprias da dinâmica do lugar. O que ocorre, porém, é que esta concepção acerca do lugar, consciente ou inconscientemente, é reproduzido pelo professor em suas práticas cotidianas e contribui para a reprodução da mesma na forma como os alunos concebem o mundo e o lugar onde vivem.

Como dissemos, pensar o lugar, e as múltiplas intencionalidades que o configuram, não é apenas tarefa da geografia. É antes ação política e pedagógica no sentido em que possibilita aos homens compreenderem o contexto, histórico e geográfico, no qual suas ações se realizam. A compreensão do lugar é elemento fundamental para que uma educação que busque possibilitar aos diferentes sujeitos a compreensão dos seus limites e possibilidades possa se realizar. Ao se alienar do lugar, o professor aliena-se de sua própria prática e reproduz a lógica que o aliena. Sem a consciência do lugar não é possível a consciência do homem como sujeito da história, da geografia, da vida, que constrói em parceria com outros homens que aprende a entender também como sujeitos, portadores dos mesmos direitos e deveres.

Daí a importância da pesquisa feita a partir da escola: desvendar as múltiplas implicações que o lugar no qual a escola está 
inserida possui; possibilitar aos sujeitos que participem da construção da escola como espaço social; permitir aos sujeitos que se reconheçam agentes da escola e que se organizem para resistir a todo e qualquer movimento que queira implodir seu caráter público em favor de interesses privados. Repensar a escola espaçotemporalmente, implica em repensar uma série de elementos que dizem respeito a forma como a sociedade da qual a escola é causa, consequência e resistência, está estruturada. Para além de mera reprodutora da sociedade, como afirmavam alguns estruturalistas, a escola é também resistência. Para tanto, é fundamental que os seus diferentes sujeitos compreendam que a pesquisa é elemento essencial para se construir uma lógica pública da produção do conhecimento. Pesquisar é partilhar informações, descrever caminhos, definir ações, refletir coletivamente, sem hierarquias em relações aqueles que dela participam.

Uma outra escola, para outros conhecimentos: eis os desafios do novos professores-pesquisadores. Eis o desafio que nos propomos a enfrentar. Político e pedagógico, tal desafio é resultado da implicação do pesquisador que entre tantos caminhos optou pelo da Educação Básica e que nela vê possibilidades de uma transformação que nasce da terra, de baixo e que busca inverter a lógica da reprodução da miséria e da riqueza que até agora foi predominante.

\section{Notas}

1. Programa das Nações Unidas para o Desenvolvimento, vinculado á ONU (Organizações das Nações Unidas), que tem como objetivo combater a pobreza no mundo. É uma instituição multilateral e existe hoje em 166 países que trabalham juntos em busca de soluções para desafios na área do desenvolvimento e sustentabilidade.

2. Faculdades de Tecnologia de São Paulo.

3. Escola Técnica Estadual.

\section{Bibliografia}

ARANTES, O.; VAINER, C.; MARICATO, E.; A cidade do Pensamento único. $3^{\circ}$ edição. Petrópolis: Vozes, 2002.

BAITZ, RICARDO. "A implicação: um novo sedimento a se explorar na Geografia?" IN Boletim Paulista de Geografia, no 84, julho de 2006. São Paulo: AGB.

BAUMAN, ZYGMUNT. Comunidade: a busca por segurança no mundo atual. Rio de Janeiro: Jorge Zahar, 2003.

CANETTI, ELIAS. Massa e poder. São Paulo: Cia das Letras, 2005.

DEMO, PEDRO. Pesquisa: princípio científico e educativo. $11^{\text {a }}$ edição. São Paulo: Cortez, 2005.

ELIAS, NOBERT. Os Estabelecidos e os Outsiders. São Paulo: Jorge Zahar, 2000.
JULIA, DOMINIQUE. "A cultura escolar como objeto histórico" IN Revista Brasileira de História da Educação, Campinas, n.1, 2001.

JUNIOR, ENIO MORO. A percepção visual de um urbano em Transição: o caso de São Caetano do Sul. Dissertação de Mestrado. São Paulo: FAUUSP, 1998.

LEFEBVRE, H. O Direito à Cidade. 30 edição. São Paulo: Centauro, 2004.

MARTINS, José de Souza. O Imaginário na Imigração Italiana. São Caetano do Sul: Fundação Pró-memória, 2003.

Diário de Fim de

século. Notas sobre o núcleo colonial de São Caetano no século XIX. São Caetano do Sul: Fundação Pró-memória, 1998. 
Escola, Lugar e Poder: uma analise

geográfica a partir de são caetano do sul, sp, brasil.pp. $77-89$

Cotidiana e história no subúrbio da cidade de São

República Velha. São Paulo: Hucitec, 1992.

Paulo: São Caetano, do fim do Império ao fim da 